\title{
(2) OPEN ACCESS \\ Severe congenital heart defects: incidence, causes and time trends of preoperative mortality in Norway
}

\author{
Gunnar Wik, ${ }^{1,2}$ Jarle Jortveit, ${ }^{3}$ Vasileios Sitras (D) , ${ }^{4}$ Gaute Døhlen, ${ }^{1}$ Arild E Rønnestad, ${ }^{5}$ \\ Henrik Holmstrøm (iD ${ }^{1}$
}

\begin{abstract}
1 Department of Paediatric Cardiology, Oslo University Hospital, Oslo, Norway ${ }^{2}$ Department of Paediatric and Adolescent Medicine, Sorlandet Hospital Kristiansand, Kristiansand, Norway

${ }^{3}$ Department of Cardiology, Sørlandet Hospital Arendal, Arendal, Norway

${ }^{4}$ Department of Obstetrics and Gynaecology, Fetal Medicine Unit, Oslo University Hospital, Oslo, Norway

${ }^{5}$ Women and Children's Division, Department of Neonatal Intensive Care, Rikshospitalet, Oslo University Hospital, Oslo, Norway
\end{abstract}

Correspondence to Gunnar Wik, Department of Paediatric Cardiology, Oslo University Hospital, Oslo 0424 Norway;

gunnarwik72@gmail.com

Received 17 May 2019

Revised 16 December 2019

Accepted 22 January 2020

Published Online First

12 February 2020

\begin{abstract}
Background and aims Severe congenital heart defects (CHDs) still represent one of the main causes of infant death. The risk factors associated with cardiac surgery and postoperative mortality are well known. We aimed to describe the rates, causes and time trends of mortality before surgery_-including termination of pregnancies and palliative care-in fetuses and children below 2 years of age with severe CHDs.
\end{abstract}

Methods and results Data concerning all 789345 pregnancies in Norway from 2004 to 2016 were retrieved from the Medical Birth Registry of Norway, the Oslo University Hospital's Clinical Registry for Congenital Heart Defects, the Norwegian Cause of Death Registry, the National Registry, Statistics Norway, autopsy reports and medical records. When including termination of pregnancy and stillbirths, the number of fetuses and children with severe CHDs that did not reach the age of 2 years was 31\%. Mortality among the 2359 live-born infants with severe CHDs was $10 \%$, of whom $58 \%$ died before surgery. Of the preoperative deaths, $81 \%$ died in a palliative care setting, and comorbidity and univentricular CHDs were common among these infants. Together, palliative care and termination of pregnancy accounted for $86 \%$ of deaths in cases of severe CHDs, and this proportion increased during the study period (annual percent changes $1.3,95 \% \mathrm{Cl} 0.4$ to 2.1 , $\mathrm{p}<0.001)$, mainly due to an increased termination rate. Conclusions Termination of pregnancy accounted for the majority of the deaths in fetuses and children with severe CHDs. Among live-born children, most preoperative deaths occurred in a palliative care setting and were strongly related to comorbidities and/or univentricular hearts.

\section{INTRODUCTION}

Congenital heart defects (CHDs) are the most common birth defects, affecting approximately $1 \%$ of newborns. ${ }^{1-3}$ The prevalence of live-born infants with severe CHDs has decreased, probably due to increased rates of prenatal detection and termination of pregnancy. ${ }^{14-7}$ CHDs still represent one of the main causes of death in neonates and young children, despite major advancements in treatment during the last decades. ${ }^{8-10}$ Several studies report high rates of comorbidity and mortality among infants with severe CHDs. ${ }^{2311}$ The mortality rate and risk factors (eg, CHD type, procedure, age, comorbidity and ethnicity) for early postoperative death and adverse outcomes in the year after discharge in children with severe CHDs have been extensively described. ${ }^{12-17}$ However, population-based studies
What is already known on this topic?

- The peroperative and postoperative mortality in children with congenital heart defects (CHDs) has decreased in recent decades.

- CHDs still represent one of the main causes of death in infants and young children.

\section{What this study adds?}

The majority of the preoperative deaths among live-born children with severe CHDs occurred in a palliative care setting.

- Unexpected deaths before surgery were rare.

- Terminated pregnancies and palliative care accounted for $86 \%$ of all deaths before 2 years of age.

investigating long-term outcomes of children born with severe CHDs are sparse. ${ }^{18}$

Moreover, there is limited knowledge on the rates and causes of preoperative mortality in infants with severe CHDs. Some of these infants die without surgical treatment in a palliative care setting. It is unknown whether the increased rate of terminated pregnancies has reduced the proportion of palliative care among infants with severe CHDs.

Norwegian national health registries provide an opportunity to conduct a nationwide populationbased study of early mortality in children with severe CHDs.

The aims of the present study were to describe the rates, causes and time trends of mortality before surgery-including termination of pregnancies and palliative care-in fetuses and children below 2 years of age with severe CHDs during the period 2004-2016 in Norway.

\section{METHODS}

\section{Classification of CHDs}

$\mathrm{CHDs}$ are defined as structural abnormalities of the heart or intrathoracic vessels with functional or potentially functional significance. ${ }^{19}$ Children with isolated cardiomyopathies, primary arrhythmias and primary pulmonary hypertension were not included in the study. Heterotaxia, transposition of the great arteries, tetralogy of Fallot, double-outlet right ventricle, truncus arteriosus, aortic arch hypoplasia, coarctation of the aorta, atrioventricular septal defects, anomalous pulmonary venous return, 
hypoplastic left heart syndrome, Shone's syndrome, aortic valve stenosis, pulmonary valve atresia, tricuspid valve atresia, Ebstein's anomaly, anomalies of the coronary arteries and other complex defects were classified as severe CHDs and included in the study. ${ }^{2021}$ Ventricular septal defects (VSDs) were classified as severe if treated by a surgical or catheter-based procedure or if the child with a non-restrictive VSD died in elective palliative care. Non-severe CHDs (atrial septal defects, restrictive VSDs, minor valve malformation, pulmonary valve stenosis and isolated patent ductus arteriosus) were not included. All individuals were assigned to only one CHD diagnosis according to the International Paediatric and Congenital Cardiac Code by two experienced paediatric cardiologists ( $\mathrm{HH}$ and GW). ${ }^{22}$

\section{Data sources}

Information about all pregnancies from 1 January 2004 to 31 December 2016 was obtained from the Medical Birth Registry of Norway (MBRN). ${ }^{23}$ Registration of pregnancy beyond 12 weeks is statutory in Norway. The MBRN contains information on all live births, stillbirths and terminations of pregnancies due to congenital anomalies after 12 weeks' gestation. Information on live-born children with severe CHDs was retrieved from the Oslo University Hospital's Clinical Registry for Congenital Heart Defects, which contains information on all children with CHDs who have been examined or treated at Oslo University Hospital. Oslo University Hospital is the national centre for invasive treatment of children with CHDs in Norway. This registry was linked to the Norwegian Cause of Death Registry and the National Registry, which contains death certificate information about the date and causes of death. Moreover, we reviewed the medical records and the autopsy reports for all live-born infants with severe CHDs who died during the study period. The overall number of deaths in children under the age of 2 years in Norway during the study period was retrieved from Statistics Norway. ${ }^{24}$

\section{Definitions}

Palliative care was defined as supportive care with refrainment from cardiac surgery and other active life-prolonging treatment. ${ }^{25} 26$ We differentiated between children who were not offered surgery and refrainment from cardiac surgery. Not offered surgery was defined as children in whom there was no feasible surgical option (such as univentricular hearts with severe pulmonary vein stenosis or pulmonary atresia with VSD and lacking ordinary pulmonary arteries). Refrainment from cardiac surgery was defined as palliative care chosen after dialogue with the parents and caretakers based on a total evaluation of the baby's condition and expected quality of life (eg, severe CHDs with comorbidities such as multiple malformations). Unexpected death was defined as preoperative death occurring in children with planned active treatment. Comorbidity was defined as a condition with anticipated effect on the child's health and/or development and included Trisomy 13, 18 and 21, other genetic syndromes, multiple malformations, intraventricular haemorrhage grade 3-4 or ischaemic brain injury, ${ }^{27}$ organ failure (eg, severe kidney failure, liver failure and necrotising enterocolitis) and extreme prematurity ( $<28$ weeks' gestation). The number of fetuses with severe CHDs was defined as the sum of terminated pregnancies, stillbirths and live births with severe CHDs

\section{Norwegian legislation and the process of counselling}

In Norway, women have the right to terminate pregnancy on demand within the first 12 weeks of gestation. Thereafter, women can apply to a medical assessment board for termination

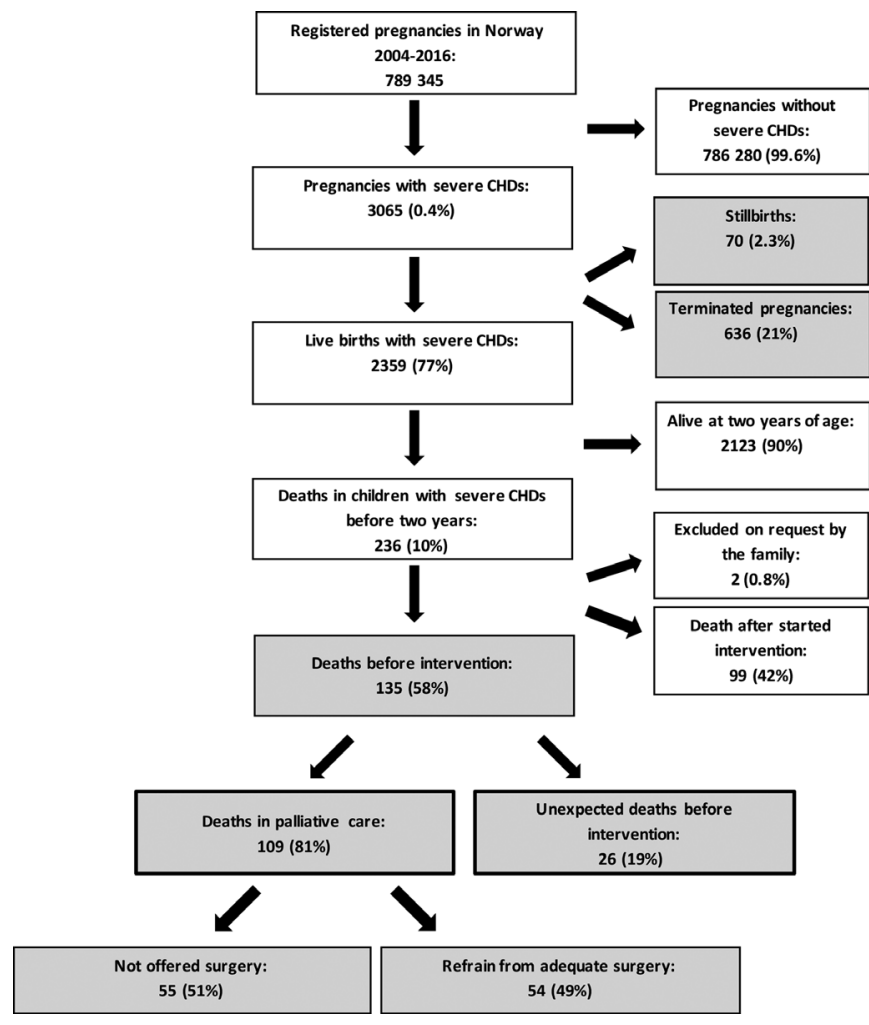

Figure 1 Flow chart of the study population. CHDs, congenital heart defects.

until week 22. Terminations for medical reasons between weeks 12 and 22 will usually be approved if the child has poor prognosis and/or comorbidities with expected major impact on quality of life.

The routine ultrasound examination in Norway is offered to all pregnant women between weeks 18 and 20. Women carrying a fetus with a suspected CHD are referred to specialised fetal medicine centres at the university hospitals. Parental counselling, by a fetal medicine specialist and a paediatric cardiologist, is individualised, based on the diagnosed CHD and presence of comorbidities, and non-directive.

\section{Statistical analysis}

Continuous variables are presented as median (range) and categorical variables as number and proportion. Time trends were analysed (log-linear model) using the Joinpoint Regression Program (version 4.0; SEER software, National Cancer Institute, USA) and are presented as the expected annual percent changes (APC) with a 95\% CI. Other statistical analyses were performed using STATA/SE V.15.0.

\section{RESULTS}

A total of 789345 pregnancies were recorded in Norway from 2004 to $2016 .^{23}$ Severe CHDs were detected in 3065 (0.39\%) cases, either prenatally or postnatally. Of these, 2359 (77.0\%) children were live born (figure 1). The proportion of live-born children with severe CHDs decreased significantly (APC -1.9 , $95 \% \mathrm{CI}-2.6$ to $1.1, \mathrm{p}<0.001)$. A total of $942(31 \%)$ fetuses and children with severe CHDs were either stillborn $(n=70)$, terminated $(n=636)$ or died before 2 years of age $(n=236)$. The rate of fetuses and children with severe $\mathrm{CHDs}$ that did not reach the age of 2 years increased significantly (APC 1.7, 95\% CI 0.1 to $3.3, p<0.001)$ during the study period. The annual number 


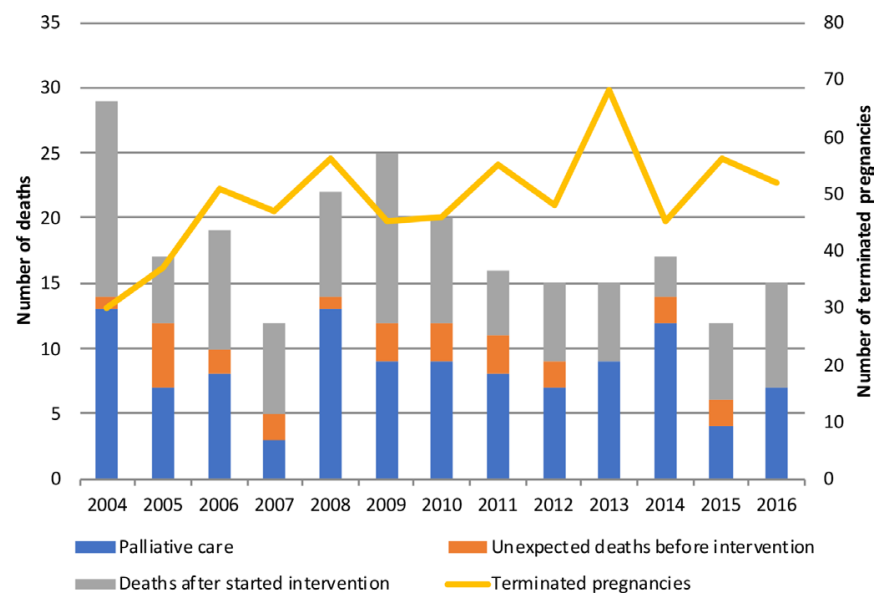

Figure 2 Terminated pregnancies, palliative care and unexpected deaths before 2 years of age in children with severe congenital heart defects in Norway 2004-2016.

of deaths are presented in figure 2. Two live-born infants with severe CHDs were excluded from detailed analysis on request by their parents.

\section{Termination of pregnancy}

Termination of pregnancy was chosen in 636 (21\%) of the 3065 cases with severe CHDs. The proportion of termination of pregnancy increased from less than 15\% in 2004 to approximately $25 \%$ in 2016 (APC 4, 95\% CI 1.7 to $6.4, \mathrm{p}<0.001$ ). This accounted for $68 \%$ (636 of 942) of all deaths before 2 years of age in cases with severe CHDs.

\section{Mortality in live-born children}

A total of $236(10.0 \%)$ of 2359 live-born children with severe CHDs died before 2 years of age. In comparison, the mortality rate for all live-born children below 2 years of age in Norway was $0.3 \%(n=2298) .{ }^{24}$ Infants with severe CHDs accounted for $10.3 \%$ of these deaths, the proportion was stable throughout the period (APC $-0.5,95 \% \mathrm{CI}-4.1$ to $3.1, \mathrm{p}=0.7$ ), and most of the deaths in live-born infants with severe CHDs occurred during the first year of life $(n=219,93 \%)$. Of the 234 children who died before 2 years of age, 135 (58\%) died before surgery. The proportion of preoperative deaths was stable throughout the study period (APC 2.0, 95\% CI -1.4 to $5.4, \mathrm{p}=0.2$ ).

\section{Unexpected preoperative deaths}

Unexpected deaths before surgery occurred in $26(1.1 \%)$ of 2359 live-born infants with severe CHDs, corresponding to $11 \%$ of the 234 live-born children with severe CHDs who died before 2 years of age and were included in the study. These infants comprised a heterogeneous group including 17 different CHDs. They have not been further analysed in this study.

\section{Palliative care}

Of the 234 live-born children with severe CHDs who died before 2 years of age and were included in the study, 109 (47\%) died in a palliative care setting. This accounts for 81\% (109 of 135) of the preoperative deaths. Among these, 55 (50\%) infants were not offered surgery (eg, hypoplastic left heart syndrome and additional pulmonary vein stenosis or severe valve-dysplasia $(n=9)$, pulmonary atresia with coronary abnormalities or lacking native pulmonary arteries $(n=5)$ and unbalanced atrioventricular septal defects with severe valve dysplasia or peripheral pulmonary stenoses $(\mathrm{n}=5))$. Refrainment from cardiac surgery was chosen in $54(50 \%)$ infants. The proportion of palliative care offered to live-born infants with severe CHDs was stable throughout the study period (APC $-0.6,95 \% \mathrm{CI}-6.2$ to $5.4, \mathrm{p}=0.8$ ). The cardiac diagnoses in infants offered palliative care are listed in figure 3 , and clinical characteristics are presented in table 1.

The median survival time in infants offered palliative care was 9 days with a range from 0 to 618 days. After the decision to provide solely palliative care, 20 (18\%) of 109 infants were discharged and died at home.

\section{Comorbidity}

A total of 73 (67\%) infants offered palliative care had additional morbidities. Of these, five (7\%) had trisomy 21, 20 (27\%) had trisomy 13 or 18 and 10 (14\%) had other genetic syndromes. Additional malformations were diagnosed in 29 (40\%) children. Four $(5 \%)$ infants had intraventricular haemorrhage grade 3-4 or ischaemic brain injury, whereas three (4\%) infants had other organ failure as the main non-cardiac diagnosis. Five (7\%) infants were born extremely preterm, of whom two had Down syndrome and one DiGeorge syndrome. Among the 14 infants with refrainment from cardiac surgery and no comorbidity, the vast majority $(n=12,86 \%)$ had hypoplastic left heart syndrome.

\section{Terminated pregnancies and palliative care}

Together, terminated pregnancies $(n=636)$ and infants offered palliative care $(n=109)$ accounted for $86 \%(n=745)$ of all deaths in cases of severe CHDs $(n=870)$, and this proportion increased significantly during the study period (APC 1.3 , 95\% CI 0.4 to 2.1, $\mathrm{p}<0.001)$.

\section{DISCUSSION}

In this nationwide study, the number of fetuses and children with severe CHDs that did not reach the age of 2 years was $31 \%$. Termination of pregnancy accounted for about two-thirds of these cases, and the proportion of terminated pregnancies increased markedly from 2004 to 2016. Mortality among the live-born children with severe CHDs was $10 \%$, of whom $58 \%$ died before surgery. More than $80 \%$ of the preoperative deaths occurred in a palliative care setting, and the proportion of palliative care was stable throughout the period. Comorbidities and univentricular CHDs were common among these infants. Approximately 10\% of deceased live-born children with severe CHDs died unexpectedly before surgery.

Termination of about half of pregnancies with prenatally diagnosed severe CHDs has been recently reported. ${ }^{28}$ We previously reported that the prenatal detection rate in Norway in 2016 was $58 \%{ }^{29}$ In the present study, we were not able to include the prenatal detection rate for all fetuses with severe CHDs, but we registered an increased rate of terminated pregnancies during the study period. In fact, at the end of the study period, approximately one quarter of all pregnancies with severe CHDs were terminated. This finding might indicate that improved prenatal detection of CHDs may result in increasing termination of fetuses with severe CHDs.

The impact of prenatal detection of CHDs on neonatal outcome is unclear. Some studies reported increased survival in live-born infants with severe CHDs, partly as a consequence of the more frequent use of termination of pregnancy. ${ }^{40}$ In contrast, a recent study reported no difference in mortality in infants with and without prenatal diagnosis of severe CHDs and questioned the impact of prenatal diagnosis on infant survival. However, the two groups (with and without prenatal diagnosis) differed in the types 


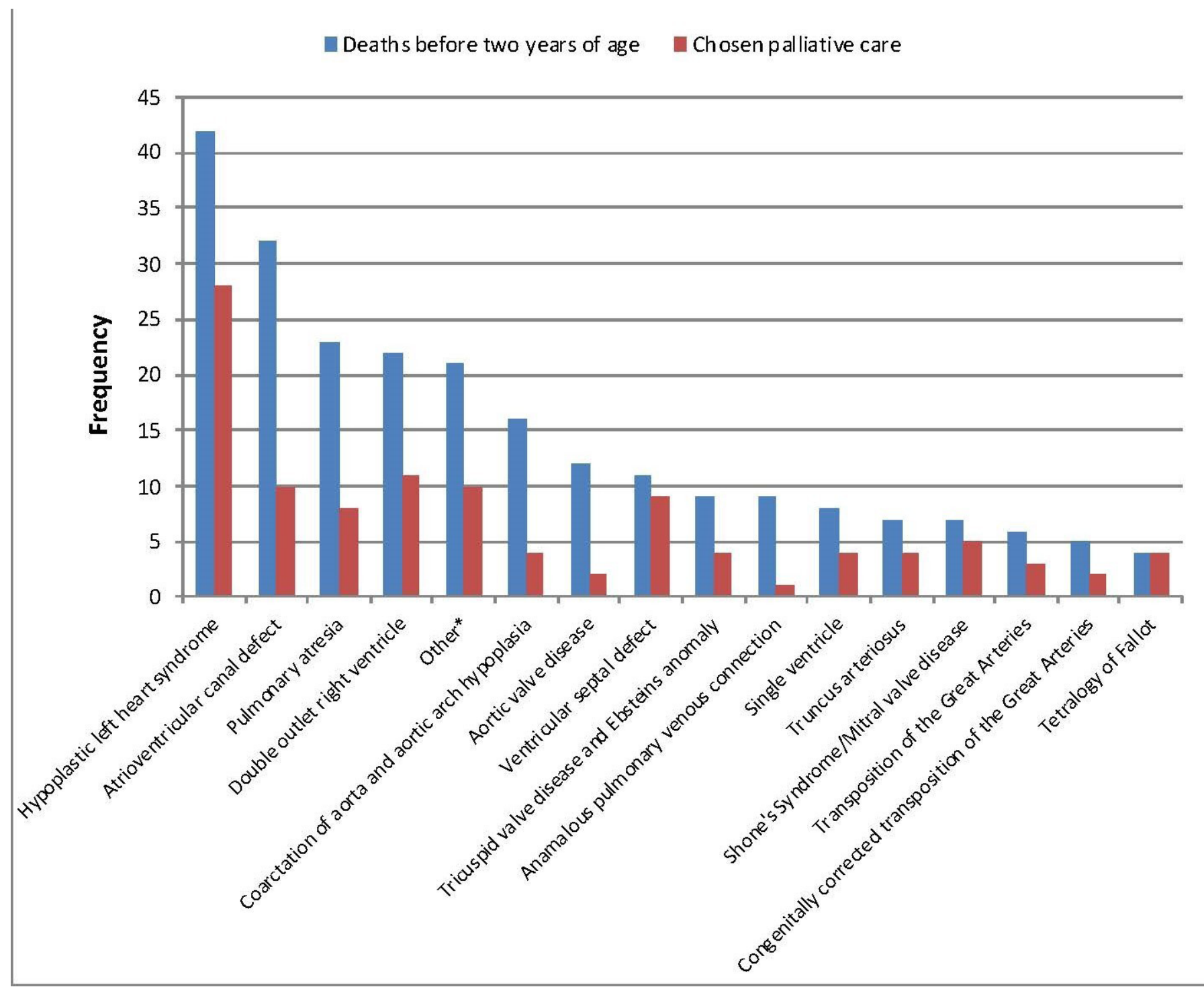

Figure 3 Diagnoses in deaths before 2 years of age in live-born children with severe congenital heart defects. Norway 2004-2016. * Heterotaxia, pulmonary venous stenosis, coronary artery anomaly and other complex defects.

of heart diagnoses. ${ }^{28}$ In the present study, the 2-year mortality rate among live-born infants was $10 \%$ and almost $50 \%$ died in palliative care. This proportion was stable despite increased termination rates. This result may illustrate how challenging it is to predict the severity of CHD and associated comorbidities during the second trimester and before the legal limit for termination of pregnancy. Moreover, the decision for the termination of pregnancy is ethically challenging. It is influenced by personal beliefs and probably involves more than just considerations around severity and survival. Genetic syndromes and coexisting malformations were major determinants when refrainment from cardiac surgery was chosen. Other comorbidities, such as severe intracerebral haemorrhage and extreme prematurity, were also important. The presence of additional cardiac defects was a determining factor when not offering surgery, particularly in children with univentricular heart defects. Several studies present a trend towards more cardiac surgery in infants with complex CHDs and severe comorbidity, such as trisomy 18 and $13 .{ }^{31}$ In the study by Vincenti et $a l^{28}$, all infants received active treatment regardless of the severity of CHDs or comorbidities, but the mortality rate was similar to the mortality in our study. This may indicate that a palliative approach mainly changes the manner of death without increasing the rate of mortality. Palliative care of the newborn is a challenging and developing arena, ${ }^{25} 3334$ and this study confirms that it is an important part of neonatal cardiology practice. An active approach involving heart surgery and intensive care is associated with painful procedures, stress and less parental involvement, ${ }^{35}$ and a comprehensive palliative approach may be preferable in selected cases.

The main strength of this study is the complete national cohort of severe CHDs, including both live-born children and terminated pregnancies. The use of national registries and access to medical records ensure the inclusion of nearly all cases of severe CHDs with detailed medical information.

However, some limitations have to be acknowledged. The number of deaths was limited, and the time trends should be interpreted with caution. We cannot exclude the possibility that some patients may have died before surgery without being recorded in the registries. Furthermore, we used arbitrary definitions of comorbidity, and the classification was based on our assessment. The same applies for the causes of refrainment from cardiac surgery. The distinction between 'not offered surgery' and 'refrainment from cardiac surgery' was not clear in all cases. We 
Table 1 Characteristics of children with severe congenital heart defects and death in a setting of palliative care,. Norway 2004-2016

\begin{tabular}{|c|c|c|c|c|c|c|c|}
\hline IPCCC diagnoses & n & $\begin{array}{l}\text { Prenatal } \\
\text { detection, } \\
\mathrm{n}(\%)\end{array}$ & $\begin{array}{l}\text { Refrainment from } \\
\text { adequate cardiac } \\
\text { surgery, } \mathrm{n}(\%)\end{array}$ & $\begin{array}{l}\text { Not offered } \\
\text { cardiac surgery, } \\
\mathrm{n}(\%)\end{array}$ & $\begin{array}{l}\text { Comorbidity, } \\
\mathrm{n}(\%)\end{array}$ & $\begin{array}{l}\text { Prematurity, } \\
\mathrm{n}(\%)\end{array}$ & $\begin{array}{l}\text { Median time } \\
\text { to death (days } \\
\text { (range)) }\end{array}$ \\
\hline Hypoplastic left heart syndrome & 28 & $12(43)$ & $14(50)$ & $14(50)$ & $6(21)$ & $6(21)$ & $8(1-154)$ \\
\hline Double outlet right ventricle & 11 & $7(64)$ & $6(55)$ & $5(45)$ & $9(82)$ & $7(64)$ & $5(0-110)$ \\
\hline Atrioventricular septal defect & 10 & $5(50)$ & $5(50)$ & $5(50)$ & $8(80)$ & $5(50)$ & $5(0-618)$ \\
\hline Ventricular septal defect & 9 & $2(22)$ & $9(100)$ & $0(0)$ & $9(100)$ & $2(22)$ & $13(2-69)$ \\
\hline Pulmonary atresia & 8 & $4(50)$ & $1(13)$ & $7(88)$ & $6(75)$ & $1(13)$ & $10(4-59)$ \\
\hline Coarctation of aorta and aortic arch hypoplasia & 4 & $1(25)$ & $4(100)$ & $0(0)$ & $4(100)$ & $2(50)$ & $7(5-51)$ \\
\hline Tricuspid valve disease and Ebstein's anomaly & 4 & $4(100)$ & $0(0)$ & $4(100)$ & $4(100)$ & $2(50)$ & $5(2-21)$ \\
\hline Single ventricle & 4 & $2(50)$ & $3(75)$ & $1(25)$ & $3(75)$ & $1(25)$ & $290(11-447)$ \\
\hline Truncus arteriosus & 4 & $2(50)$ & $3(75)$ & $1(25)$ & $4(100)$ & $2(50)$ & $15(12-36)$ \\
\hline Tetralogy of Fallot & 4 & $0(0)$ & $3(75)$ & $1(25)$ & $4(100)$ & $1(25)$ & $144(12-282)$ \\
\hline Transposition of the great arteries & 3 & $1(33)$ & $1(33)$ & $2(67)$ & $2(67)$ & $1(33)$ & $8(8-29)$ \\
\hline Mitral valve disease & 3 & $1(33)$ & $0(0)$ & $3(100)$ & $2(67)$ & $0(0)$ & $3(0-3)$ \\
\hline Othert & 17 & $11(65)$ & $5(29)$ & $12(71)$ & $12(71)$ & $3(18)$ & $16(1-416)$ \\
\hline Total & 109 & $52(48)$ & $54(50)$ & $55(50)$ & $73(67)$ & $33(30)$ & $9(0-618)$ \\
\hline
\end{tabular}

*Gestational age $<37$ weeks.

tHeterotaxia, aortic valve disease, anomalous pulmonary venous connection, congenitally corrected transposition of the great arteries, Shone's syndrome, pulmonary venous stenosis, coronary artery anomaly and other complex defects.

IPCCC, International Paediatric and Congenital Cardiac Code.

have no information about comorbidity and specific diagnosis of the heart defect in the terminated pregnancies with severe CHDs. Finally, we emphasise that clinical practice varies between countries depending on factors like the healthcare system, socioeconomic conditions, culture and religion. This study reflects the situation in Norway, and the findings are not automatically transferrable to other settings.

In conclusion, we found lower mortality than previously reported among live-born infants with severe CHDs. Moreover, the data revealed an increasing number of fetuses and infants not offered active life prolonging treatment.

We emphasise the importance of optimised antenatal service and decision-making processes, including the indications for surgery versus palliative care in live-born children. In our opinion, providing palliative care in the most complex cases may in fact improve quality of life for the affected infants and their families, without necessarily increasing the mortality rate.

Contributors GW contributed to the study concept and design, data collection and interpretation, literature review and revised and approved the manuscript. JJ contributed to the study concept and design, data interpretation, literature review and revised and approved the manuscript. VS contributed to the study concept, literature review and revised and approved the manuscript. GD and AER contributed to the study concept and revised and approved the manuscript. HH contributed to the study concept and design, data interpretation, literature review and revised and approved the manuscript.

Funding This work was supported by the Norwegian Association for Children with Congenital Heart Disease, the Oslo University Hospital and Sorlandet Hospital HF, Norway.

Disclaimer The funders have no role in the design and conduct of the study, in the collection, analysis and interpretation of the data, and in the preparation, review or approval of the manuscript.

Competing interests None declared.

Patient consent for publication Not required.

Ethics approval The study was approved by the Regional Committee for Medical and Health Research Ethics South East Norway (REK nr. 2010/392).

Provenance and peer review Not commissioned; externally peer reviewed.

Data availability statement Data are stored in 'eReg Versjon 2.4.0 OUS-HF' and are available upon reasonable request. They are not to be reused without approval from the Regional Committee for Medical and Health Research Ethics South East Norway.
Open access This is an open access article distributed in accordance with the Creative Commons Attribution Non Commercial (CC BY-NC 4.0) license, which permits others to distribute, remix, adapt, build upon this work non-commercially, and license their derivative works on different terms, provided the original work is properly cited, appropriate credit is given, any changes made indicated, and the use is non-commercial. See: http://creativecommons.org/licenses/by-nc/4.0/.

\section{ORCID iDs}

Vasileios Sitras http://orcid.org/0000-0003-3264-3302

Henrik Holmstrøm http://orcid.org/0000-0003-4745-5267

\section{REFERENCES}

1 Leirgul E, Fomina T, Brodwall K, et al. Birth prevalence of congenital heart defects in Norway 1994-2009--a nationwide study. Am Heart J 2014;168:956-64.

2 Oster ME, Lee KA, Honein MA, et al. Temporal trends in survival among infants with critical congenital heart defects. Pediatrics 2013;131:e1502-8.

3 Steurer MA, Baer RJ, Keller RL, et al. Gestational age and outcomes in critical congenital heart disease. Pediatrics 2017;140:e20170999.

4 Jortveit J, Øyen N, Leirgul E, et al. Trends in mortality of congenital heart defects. Congenit Heart Dis 2016;11:160-8.

5 Khoshnood B, Loane M, Garne E, et al. Recent decrease in the prevalence of congenital heart defects in Europe. J Pediatr 2013;162:e102:108-13.

6 Khoshnood B, De Vigan C, Vodovar V, et al. Trends in prenatal diagnosis, pregnancy termination, and perinatal mortality of newborns with congenital heart disease in France, 1983-2000: a population-based evaluation. Pediatrics 2005;115:95-101.

7 Dolk H, Loane M, Garne E, et al. Congenital heart defects in Europe: prevalence and perinatal mortality, 2000 to 2005. Circulation 2011;123:841-9.

8 Gilboa SM, Salemi JL, Nembhard WN, et al. Mortality resulting from congenital heart disease among children and adults in the United States, 1999 to 2006. Circulation 2010;122:2254-63.

9 Kurinczuk JJ, Hollowell J, Boyd PA. The contribution of congenital anomalies to infant mortality. Oxford: National Perinatal Epidemiology Unit, University of Oxford, 2010.

10 Knowles RL, Bull C, Wren C, et al. Mortality with congenital heart defects in England and Wales, 1959-2009: exploring technological change through period and birth cohort analysis. Arch Dis Child 2012;97:861-5.

11 Eskedal L, Hagemo P, Eskild A, et al. A population-based study of extra-cardiac anomalies in children with congenital cardiac malformations. Cardiol Young 2004;14:600-7.

12 Crowe S, Brown KL, Pagel C, et al. Development of a diagnosis- and procedure-based risk model for 30-day outcome after pediatric cardiac surgery. J Thorac Cardiovasc Surg 2013;145:1270-8.

13 Jenkins KJ, Gauvreau K, Newburger JW, et al. Consensus-based method for risk adjustment for surgery for congenital heart disease. J Thorac Cardiovasc Surg 2002;123:110-8.

14 Lacour-Gayet F, Clarke D, Jacobs J, et al. The Aristotle score: a complexity-adjusted method to evaluate surgical results. Eur J Cardiothorac Surg 2004;25:911-24. 
15 O'Brien SM, Clarke DR, Jacobs JP, et al. An empirically based tool for analyzing mortality associated with congenital heart surgery. J Thorac Cardiovasc Surg 2009; 138:1139-53.

16 Crowe S, Ridout DA, Knowles R, et al. Death and emergency readmission of infants discharged after interventions for congenital heart disease: a national study of 7643 infants to inform service improvement. J Am Heart Assoc 2016;5. doi:10.1161/ JAHA.116.003369. [Epub ahead of print: 20 May 2016].

17 Knowles RL, Ridout D, Crowe S, et al. Ethnic-specific mortality of infants undergoing congenital heart surgery in England and Wales. Arch Dis Child 2019;104:844-50.

18 Best KE, Rankin J, JJJotAHA R. Long-term survival of individuals born with congenital heart disease: a systematic review and meta-analysis. J Am Heart Assoc 2016;5:e002846.

19 Mitchell SC, Korones SB, Berendes HW. Congenital heart disease in 56, 109 births. incidence and natural history. Circulation 1971;43:323-32.

20 Hoffman JIE, Kaplan S. The incidence of congenital heart disease. J Am Coll Cardiol 2002;39:1890-900.

21 Jortveit J, Eskedal L, Hirth A, et al. Sudden unexpected death in children with congenital heart defects. Eur Heart J 2016;37:621-6.

22 International Society for Nomenclature of Paediatric and Congenital Heart Disease. International paediatric and congenital cardiac code, 2005. Available: http://ipccc.net

23 Health NIoP. Medical birth registry of Norway, 2019. Available: http://statistikkbank. fhi.no/mfr/ [Accessed Feb 2019].

24 Statistics Norway. Statistisk sentralbyrå, 2018. Available: https://www.ssb.no/ befolkning/statistikker/fodte/aar [Accessed 31 Oct 2018].

25 de Rooy L, Aladangady N, Aidoo E. Palliative care for the newborn in the United Kingdom. Early Hum Dev 2012;88:73-7.
26 British Association of Perinatal Medicine Working Group. Palliative care (supportive and end of life care): a framework for clinical practice in perinatal medicine, 2010. Available: https://www.bapm.org/sites/default/files/files/Palliative_care_final_ version_\%20Aug10.pdf

27 Papile LA, Burstein J, Burstein R, et al. Incidence and evolution of subependymal and intraventricular hemorrhage: a study of infants with birth weights less than 1,500 GM. J Pediatr 1978;92:529-34.

28 Vincenti M, Guillaumont S, Clarivet B, et al. Prognosis of severe congenital heart diseases: do we overestimate the impact of prenatal diagnosis? Arch Cardiovasc Dis 2019;112:261-9.

29 Jortveit J, Wik G, Ødegaard JS, et al. Diagnosis of severe congenital heart defects in Norway 2016. Tidsskr Nor Laegeforen 2019;139.

30 Wren C, Irving CA, Griffiths JA, et al. Mortality in infants with cardiovascular malformations. Eur J Pediatr 2012;171:281-7.

31 Olsen M, Christensen TD, Pedersen L, et al. Late mortality among Danish patients with congenital heart defect. Am J Cardiol 2010;106:1322-6.

32 Brown KL, Crowe S, Franklin R, et al. Trends in 30-day mortality rate and case mix for paediatric cardiac surgery in the UK between 2000 and 2010. Open Heart 2015;2:e000157.

33 Parravicini E. Neonatal palliative care. Curr Opin Pediatr 2017;29:135-40.

34 Wool C, Côté-Arsenault D, Perry Black B, et al. Provision of services in perinatal palliative care: a multicenter survey in the United States. J Palliat Med 2016;19:279-85.

35 Woolf-King SE, Anger A, Arnold EA, et al. Mental health among parents of children with critical congenital heart defects: a systematic review. J Am Heart Assoc 2017;6:e004862. 